Abstract

\title{
Organometallic Nucleosides: Synthesis and Biological Evaluation of Substituted Dicobalt Hexacarbonyl Alkynyl Modified 2'-Deoxyuridines ${ }^{\dagger}$
}

\author{
Roman Dembinski ${ }^{1,2, *}$, Renata Kaczmarek ${ }^{1}$, Dariusz Korczyński ${ }^{1}$ and \\ Karolina Królewska-Golińska ${ }^{1}$ \\ 1 Centre of Molecular and Macromolecular Studies, Polish Academy of Sciences, Sienkiewicza 112, \\ 90-363 Łódź, Poland \\ 2 Department of Chemistry, Oakland University, 146 Library Drive, Rochester, MI 48309-4479, USA \\ * Correspondence: dembinsk@oakland.edu \\ + Presented at the 2nd Molecules Medicinal Chemistry Symposium (MMCS): Facing Novel Challenges in \\ Drug Discovery, Barcelona, Spain, 15-17 May 2019.
}

Published: 12 August 2019

\begin{abstract}
In continuation of synthetic pursuit of metallo-nucleosides, in particular dicobalt hexacarbonyl 5-alkynyl-2'-deoxyuridines, novel compounds with alkynyl groups were synthesized, starting from 5-iodo-2'-deoxyuridine. Reactions of dicobalt octacarbonyl $\left[\mathrm{Co}_{2}(\mathrm{CO}) 8\right]$ with 2'-deoxy5 -oxopropynyluridines and related compounds gave dicobalt hexacarbonyl nucleoside complexes (83-31\%). The growth inhibition of HeLa and K562 cancer cell lines by organometallic nucleosides was examined and compared to that by alkynyl nucleoside precursors. Coordination of the dicobalt carbonyl moiety to the 2'-deoxy-5-alkynyluridines led to a significant increase in its cytotoxic potency. The cobalt compounds antiproliferative activities against the HeLa cell line and the K562 cell line will be described. Coordination of an acetyl-substituted cobalt nucleoside was expanded using the 1,1-bis(diphenylphosphino)methane (dppm) ligand, resulting in cytotoxicity at comparable levels. The formation of reactive oxygen species in the presence of cobalt compounds was determined in K562 cells. The results indicate that the mechanism of action for most antiproliferative cobalt compounds may be related to the induction of oxidative stress.
\end{abstract}

Keywords: modified nucleosides; cobalt carbonyl complexes; antiproliferative activity

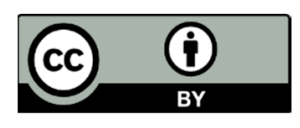

(C) 2019 by the authors. Licensee MDPI, Basel, Switzerland. This article is an open access article distributed under the terms and conditions of the Creative Commons Attribution (CC BY) license (http://creativecommons.org/licenses/by/4.0/). 